\title{
Separate effects of irradiation and of graft-versus-host reaction on rat mucosal mast cells
}

\author{
A G CUMMINS, G H MUNRO, J F HUNTLEY, H R P MILlER, \\ AND ANNE FERGUSON \\ From the Gastrointestinal Unit, University of Edinburgh and Western General Hospital, Edinburgh and \\ Moredun Research Institute, Edinburgh
}

SUMmary T cell mediated immune responses in the gut can produce enteropathy and malabsorption. We have investigated the relevance of mucosal mast cells (MMC) to the mechanisms of this enteropathy by using graft-versus-host reaction (GvHR) in the rat as a model of mucosal delayed type hypersensitivity. Measurements of mucosal architecture, intraepithelial lymphocytes (IEL) and MMC counts were performed in control and experimental rats, and release of rat mast cell protease II (RMCPII) into the bloodstream was used as an index of MMC activation. In unirradiated rats, jejunal MMC count was increased on day 14 of the GvHR (mean $272 / \mathrm{mm}^{2} v 182$ in controls, $p<0 \cdot 01$ ), as was serum RMCPII $(\mathrm{p}<0 \cdot 01)$. Irradiated rats $(4 \cdot 5 \mathrm{~Gy}$, reconstituted with isogeneic spleen cells) had low counts of IEL and crypt hyperplasia seven to 14 days after irradiation. Irradiated rats with GvHR (induced by ip injection of parental strain spleen cells) and studied on days 7, 10 and 14, had significant enteropathy with longer crypts and higher CCPR than matched irradiated animals $(p<0.05$ on day 14 when compared with irradiation alone). Intraepithelial lymphocytes counts, however, reflected only the effect of radiation. Irradiation, with or without GvHR, led to the virtual disappearance of jejunal MMC, undetectable jejunal RMCPII and very low levels of RMCPII in serum (all $p<0.01$ when compared with unirradiated controls). These experiments show that there is a modest expansion in jejunal MMC in unirradiated rats with semiallogeneic GvHR, whereas irradiation, alone or associated with GvHR, profoundly depletes MMC for at least two weeks. The enteropathy of GvHR can evolve in the virtual absence of MMC.

A distinct pattern of small intestinal mucosal damage has been observed in association with local delayed type hypersensitivity reactions. Experimental models used have included allograft rejection, graftversus-host reaction (GvHR), enteral challenge after immunisation with protein antigen and parasite infections. The features described in some or all of these situations are hyperplasia of the crypts of Lieberkuhn with or without shortening of the villi; an increase in the proportion of goblet cells; brush border enzyme deficiency; increased count of intraepithelial lymphocytes (IEL); an increased mitotic

Address for correspondence: Professor Anne Ferguson. Gastrointestinal Unit. Western General Hospital. Edinburgh EH4 2XU.

Accepted for publication 18 August 1988 . index of IEL; and expression of class II antigens by crypt enterocytes (reviewed by Ferguson').

In a detailed analysis of GvHR in neonatal mice, we also observed a late but sustained increase in the count of mucosal mast cells (MMC) in the jejunal mucosa.: Changes in MMC numbers in irradiated rats with GvHR (depletion followed by expansion) have been briefly reported, ${ }^{3}$ but no details of cell counts or other quantitative assessment of MMC were given. We have therefore undertaken a series of experiments further to investigate the relationship between MMC and the intestinal mucosal damage of delayed type hypersensitivity reactions. Because mast cells of the rat are more amenable to in vivo analysis than mouse mast cells, ${ }^{+}$we have used this species; GvHR was induced in $F_{1}$ hybrid rats by 
injection of parental strain spleen cells. The primary objectives were to document whether there is indeed an expansion of MMC in adult rats with GvHR, and, by measuring release of the MMC granule protease rat mast cell protease II (RMCPII) into the bloodstream,, "to seek evidence of activation of these cells. We speculated that MMC mediators could be among the 'thymus dependent' factors responsible for T cell mediated enteropathy and associated malabsorption. In order to produce a spectrum of morphological changes in the gut mucosa, GvHR was induced in animals with and without prior irradiation of the host.

\section{Methods}

\section{ANIMALS}

Male rats of the strains $\mathrm{DA}, \mathrm{PVG}^{\mathrm{c}}, \mathrm{DA} \times \mathrm{PVG}^{\mathrm{C}} \mathrm{F}_{1}$, and $\mathrm{PVG}^{\mathrm{c}} \times \mathrm{PGV}^{\mathrm{u}} \mathrm{F}_{1}$ were either obtained directly from OLAC Ltd, Bichester, UK, or bred from stock supplied by OLAC. Different strain combinations were used in the pilot and later experiments, because of problems in the rearing of $P V G^{c} \times P^{\prime} G^{u} F_{1}$ rats.

\section{IRRADIATION}

Before irradiation, rats were sedated with $15-20 \mathrm{mg}$ ip of sodium thiobutabarbital. The irradiation source was a Siemens Stabilipan $x$-ray generator set at 250 $\mathrm{KV}(15 \mathrm{~mA})$ with a thoreasus 11 filter and a total dose of $4.50 \mathrm{~Gy}$ was delivered, animals being rotated after half the dose to equalise the field exposure.

INDUCTION OF GvHR

Donor animals were killed by cervical dislocation under ether anaesthesia, and a suspension of spleen cells in RPMI 1640 medium was prepared. Graftversus-host reaction was induced in recipient animals by ip injection of $1.3 \times 10^{\times}$viable spleen cells, and the presence of a GvHR was confirmed by calculating the spleen index ( $\mathrm{SI}),{ }^{7}$ when the animals were killed, as:

\section{Mean relative spleen weight ( $\mathrm{mg}$ spleen per $10 \mathrm{~g}$ body weight) in GvHR rats \\ mean relative spleen weight $(\mathrm{mg}$ spleen per $10 \mathrm{~g}$ body weight) in control rats}

GvHR effects on the intestinal mucosa were evaluated morphologically, by measurements of villus and crypt length, crypt cell production rate (CCPR), and counts of IEL.

COLLECTION AND PROCESSING OF SPECIMENS Animals were anaesthetised with ether and weighed, then (with the exception of rats in the pilot experiment) each was injected with $1.0 \mathrm{mg} / \mathrm{kg}$ of vincristine ip" to block accumulation of metaphases in intestinal crypts. Rats were re-anaesthetised 30-180 minutes later and the following specimens taken. (a) Blood was collected from the abdominal aorta; after clotting the serum was separated and stored at $-20^{\circ} \mathrm{C}$ for assay of RMCPII. (b) The spleen was removed and later weighed. (c) The small intestine was removed and several biopsies were taken from the proximal jejunum, $18-22 \mathrm{~cm}$ from the pylorus. (d) A piece of jejunum was weighed and then frozen for later measurement of RMCPII. (e) A biopsy was fixed in $10 \%$ buffered ( $\mathrm{pH} 7 \cdot 0)$ formalin, paraffin embedded, cut at $4 \mu \mathrm{m}$ and stained with hacmatoxylin and cosin. (f) Another biopsy was placed in Carnoy's fixative for 24 hours, stored in $100 \%$ ethanol and later processed for toluidine blue ( $\mathrm{pH} 0.5$ ) staining of MMC. (g) A biopsy was fixed in $75 \%$ ethanol $/ 25 \%$ glacial acetic acid for six hours and then stained in bulk - after acid hydrolysis at $60^{\circ} \mathrm{C}$ - with the modified Feulgen stain (Schiff reagent; Difco), for microdissection of villi and crypts.

HISTOLOGY, CELL COUNTS AND EPITHEIIAI.

CELL. KINETICS

Intraepithelial lymphocytes counts were performed on H\&E stained sections, "and expressed as numbers of IEL/100 epithelial cells. Mucosal mast cells were counted in well orientated sections, using a fixed ficld technique with a calibrated square graticule and a $\times 100$ oil immersion lens." Twenty fields per specimen were counted and the result expressed as cells per $\mathrm{mm}^{2}$.

Lengths of villi and crypts, and blocked metaphases per crypt were measured in bulk stained and microdissected specimens of jejunum." Villus and crypt lengths were expressed in $\mu \mathrm{m}$ and the CCPR in each group of animals calculated as the rate of accumulation of metaphases/crypt/hour.

QUANTITATION OF RMCPII IN TISSUES

Two to four centimetre lengths of jejunum were homogenised in three volumes of $0.15 \mathrm{M} \mathrm{KCl}$ and RMCPII content measured by single radial immunodiffusion. ${ }^{2}$

QUANTITATION OF RMCPII IN SERUM A direct ELISA method was used. Plastic 96-well microtitre plates (Titertek, Flow Laboratories) were coated with affinity purified sheep IgG anti-RMCPII antibody (in bicarbonate/carbonate buffer $\mathrm{pH} 9 \cdot 6$ ) at $1 \mu \mathrm{g} / \mathrm{ml}(150 \mu \mathrm{l} / \mathrm{well})$ overnight at $4^{\circ} \mathrm{C}$. The plates were washed with phosphate buffered saline containing $0.1 \%$ Tween 20 (PBS/T20). The next day, from a stock solution of RMCPII at $1 \mu \mathrm{g} / \mathrm{ml}$, standards between 10 and $80 \mathrm{ng} / \mathrm{ml}$ were made up in PBS/T20 containing $0.2 \%$ fetal calf scrum (PBS/T20/FCS). 
Table 1 Pilot study: spleen index of GvHR and jejunal content of RMCPII (mean $(S D))$ in untreated rats, and rats with semi-congenic $G v H R$. $(n=6)$

\begin{tabular}{|c|c|c|c|}
\hline Experimental group & Spleen index & $\begin{array}{l}\text { Jejunal RMCPII } \\
(\mu g / g \text { wet weight })\end{array}$ & $p^{*}$ \\
\hline Untreated & - & $516(56)$ & \\
\hline GvHR day 10 & 1.99 & $735(152)$ & $<0 \cdot 05$ \\
\hline GvHR day 14 & 1.64 & $1035(240)$ & $<0 \cdot 01$ \\
\hline GvHR day 21 & 1.84 & $1230(345)$ & $<0 \cdot 01$ \\
\hline
\end{tabular}

$\mathrm{p}^{*}=$ significance of difference from untreated.

These standards and serum samples $(150 \mu \mathrm{l})$ were applied in duplicate to the washed coated plates and incubated for one hour at $37^{\circ} \mathrm{C}$. The plates were washed, and sheep $\mathrm{F}(\mathrm{ab})_{2}$ anti-RMCPII horseradish peroxidase conjugate added $(150 \mu l$ of $1: 3000)$ and incubated for one hour at $37^{\circ} \mathrm{C}$. The plates were washed again and substrate added $(150 \mu \mathrm{l} 0 \cdot 04 \%$ o-phenylenediamine, $0.01 \%$ hydrogen peroxide, 100 $\mathrm{mM}$ citrate buffer $\mathrm{pH} 5 \cdot 0$ ). Absorbance was read at $492 \mu \mathrm{m}$ and concentration expressed as ng RMCPII/ $\mathrm{ml}$ of serum.

STATISTICAL ANALYSIS

In experiments involving only two groups, Student's $t$ test was used; other data were analysed by using Peritz' F test. ${ }^{1: 3}$

\section{Experiments and results}

GENERAL FEATURES

Animals with GvHR, but without irradiation, appeared completely healthy. Control, irradiated rats were lethargic for a few days and some had diarrhoea. In GvHR with irradiation, animals had features of graft-versus-host disease from about the tenth day; they were lethargic and hunched, with raised fur. All were killed on day 14, and although there were no deaths in this study, rats in other experiments have died during the third week.

\section{PILOT STUDY}

A semicongenic GvHR was induced in $\mathrm{PVG}^{\mathrm{c}} \times \mathrm{PVG}^{\mathrm{u}}$ hosts, aged 16 weeks, by ip injection of $1 \times 10^{\times} \mathrm{PVG}^{\mathrm{C}}$ spleen cells. Six uninjected animals served as controls; and six rats were killed on days 10,14, and 21 of the GvHR. Splenic index was measured, and the MMC protease RMCPII assayed in homogenate of jejunum (Table 1). The presence of a GvHR was confirmed by a high spleen index and there was a progressive rise in tissue RMCPII content with time after induction of the GvHR.

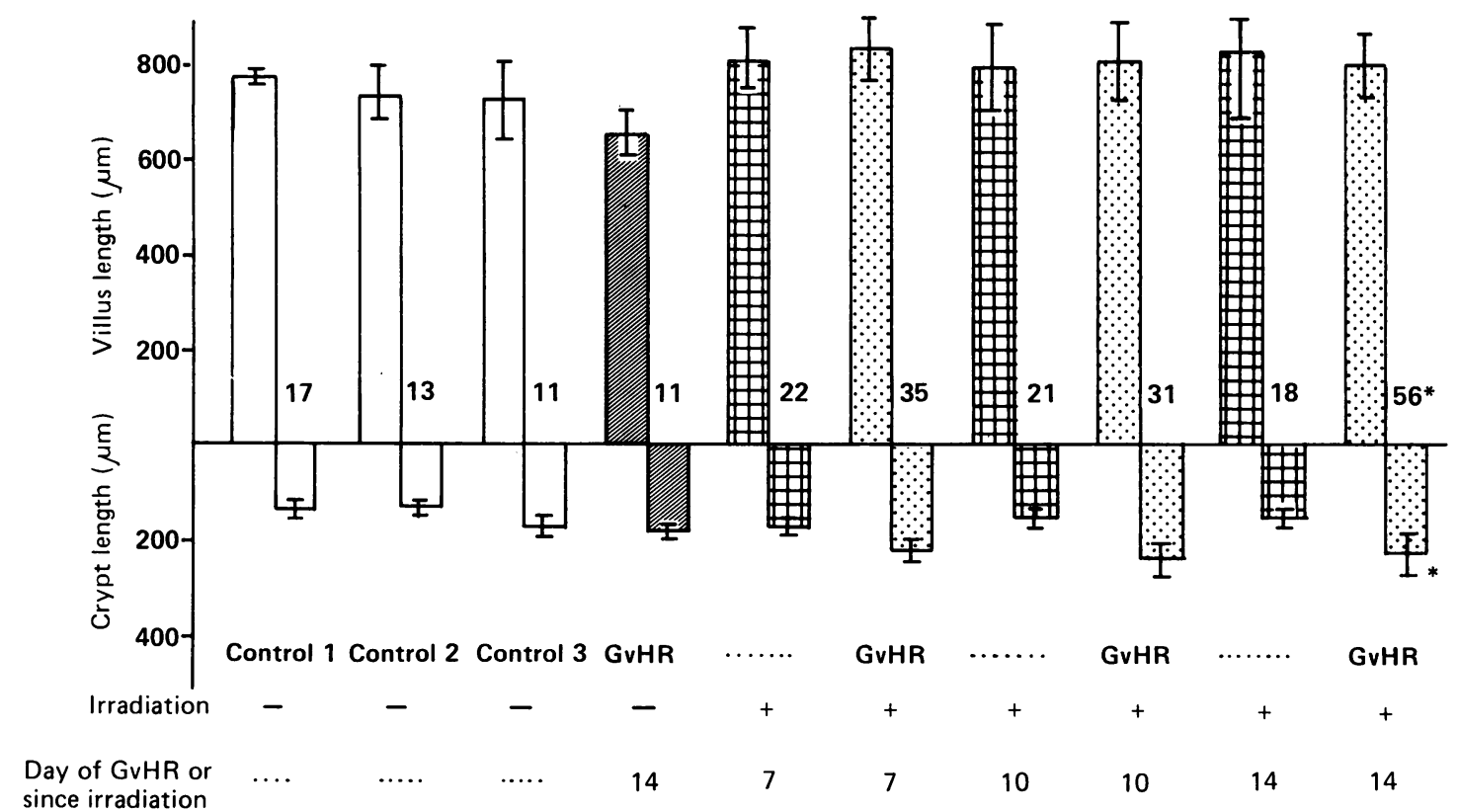

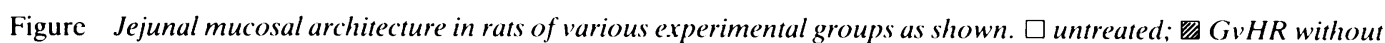

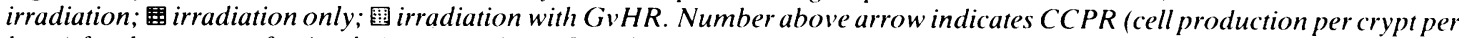
hour) for that group of animals (see text). +significantly less $(p<0 \cdot 05)$ than control $1 .{ }^{*}$ values for irradiation/GvHR group on day 14 significantly greater $(p<0.05)$ than irradiation alone day 14. 
Table 2 Counts of intraepithelial lymphorytes in rat jejunal mucosa: untreated, unirradiated with $G v H R$, irradiated/ reconstituted, and irradiated with GvHR (neur (:D))

\begin{tabular}{|c|c|c|c|c|}
\hline $\begin{array}{l}\text { Experimental } \\
\text { group }\end{array}$ & $\begin{array}{l}\text { Day of } \\
\text { GvHR or } \\
\text { post-irradn }\end{array}$ & $\begin{array}{l}\text { IEL count } \\
\text { (per lo0 } \\
\text { enterocytes) }\end{array}$ & $p^{*}$ & $\begin{array}{l}\text { poversu } \\
\text { Cl, } 2 \text { or } \\
\text { 3) }\end{array}$ \\
\hline Untreated $\mathrm{Cl}$ & - & $18 \cdot 7(2 \cdot 6)$ & & \\
\hline $\begin{array}{c}\text { GvHR (no irradn) } \\
\text { (SI } 1.57)\end{array}$ & 14 & $18 \cdot 6(5 \cdot 3)$ & & ns \\
\hline Untreated C2 & - & $16 \cdot 2(4 \cdot 4)$ & & \\
\hline Untreated C3 & - & $19 \cdot 3(5 \cdot 1)$ & & \\
\hline Irradn & 7 & $8 \cdot 9(2 \cdot 4)$ & & $<0 \cdot(01$ \\
\hline $\begin{array}{r}\text { Irradn GvHR } \\
(\text { SI } 1.8)\end{array}$ & 7 & $9 \cdot 6(2 \cdot 3)$ & $\mathrm{ns}$ & $<0 \cdot(05$ \\
\hline Irradn & 10 & $14 \cdot 9(4 \cdot 5)$ & & ns \\
\hline $\begin{array}{l}\text { Irradn GvHR } \\
\text { (SI 1.69) }\end{array}$ & 10 & $12 \cdot 9(4 \cdot 2)$ & ns & ns \\
\hline Irradn & 14 & $12 \cdot 7(2 \cdot 4)$ & & ns \\
\hline $\begin{array}{l}\text { Irradn GvHR } \\
\text { (SI 2.39) }\end{array}$ & 14 & $11 \cdot 1(4 \cdot(0)$ & ns & $\mathrm{ns}$ \\
\hline
\end{tabular}

Irradn - irradiation; $\mathrm{p}^{*}$ - significance of difference between irradiation and irradiation GvHR groups; $\mathrm{CI}$ : control to GvHR without irradiation; $\mathrm{C} 2$ : control to rats with irradiation alone; $\mathrm{C} 3$ : control to rats with irradiation/GvHR; SI: spleen index of GvHR (see text).

MUCOSAL MAST CELLS IN UNIRRADIATED RATS WITH GvHR

Graft-versus-host reaction was induced in 16 male $\mathrm{DA} \times \mathrm{PVGF}_{1}$ rats aged 10 weeks, by iv injection of $3 \times 10^{\times} \mathrm{DA}$ spleen cells. A group of 16 untreated age matched $\mathrm{DA} \times \mathrm{DVGF}_{1}$ rats was used as controls (control 1 in Tables 2 and 3 and in the Figure). All rats were killed on day 14 and the presence of GvHR in the experimental group was confirmed by a spleen index of 1.57. Effects of GvHR on intestinal morphology were confined to a small but significant reduction in mean villus height in the GvHR group
(Figure). Intraepithelial lymphocytes counts were similar in GvHR and control rats (Table 2).

Results of MMC counts and RMCPII assays are summarised in the top section of Table 3 . Jejunal MMC count and tissue RMCPII were both higher in the GvHR group than in controls although the difference was statistically significant only for MMC. Separate counts of MMC were carried out in the villus and in pericryptal lamina propria, as it has been suggested that there is redistribution of $\mathrm{MMC}$ in the mucosa in GvHR. "This was not confirmed. Mean villus MMC count was $203 / \mathrm{mm}^{2}$ in GvHR compared with 131 in controls, and mean pericryptal MMC count was 354 in GvHR, 240 in controls. Serum RMCPII content in the GvHR group was higher than in group 1 controls, but lower than in the other two batches of control animals.

\section{MUCOSAL MAST CELLS IN IRRADIATED RATS} with GvHR

In this experiment, the rats received 4.5 Gy irradiation as described above. Some were then reconstituted with $1 \times 10^{\mathrm{x}}$ isogeneic spleen cells ip; other rats had GvHR induced by ip injection of $1.3 \times 10^{\times} \mathrm{PVG}^{\mathrm{C}}$ spleen cells. For logistic reasons related to irradiation facilities, the irradiation alone and irradiation/GvHR rats were irradiated and reconstituted on two separate days and so two sets of unirradiated control rats were used (control 2 for irradiation alone, control 3 for GvHR); irradiated/reconstituted and irradiated/GvHR rats were killed in groups at seven, 10 and 14 days (six or seven rats per group). Spleen index confirmed the presence of GvHR on day seven $(1 \cdot 80)$, day $10(1 \cdot 69)$ and day $14(2 \cdot 39)$.

The morphological effects of irradiation/ reconstitution, and of a semi-allogeneic GvHR with irradiation, are illustrated in the Figure and Table 2.

Table 3 Counts of $M M C$, and jejunal and serum content of $R M C P I I$, in rats: untreated, unirradiated with (jvHR, irradiated. and irradiated with GvHR (mean (SD))

\begin{tabular}{|c|c|c|c|c|c|c|c|c|c|c|}
\hline $\begin{array}{l}\text { Experimental } \\
\text { group }\end{array}$ & $\begin{array}{l}\text { Day of } G v H R \\
\text { or post-irradn }\end{array}$ & $\begin{array}{l}M M C \\
\text { count (per } \\
\left.\mathrm{mm}^{2}\right)\end{array}$ & $p^{* k}$ & $\begin{array}{l}p \text { (versus } \\
C I, 2 \text { or } \\
3)\end{array}$ & $\begin{array}{l}\text { Jejunal RMC } P I I \\
(\mu g / g \text { wet weight })\end{array}$ & $p^{*}$ & $\begin{array}{l}\text { p (versus } \\
\text { (1, } 2 \text { or } \\
\text { 3) }\end{array}$ & $\begin{array}{l}\text { Serum } \\
\text { RMCPII } \\
(\mathrm{ng} / \mathrm{ml})\end{array}$ & $p^{*}$ & $\begin{array}{l}\text { p (versus } \\
(\%, 2 \text { or } \\
3)\end{array}$ \\
\hline Untreated Cl & - & $182(82)$ & & & 47()$(6())$ & & & $72(1)$ & & \\
\hline GvHR (no irradn) & 14 & $272(126)$ & & $<0 \cdot(01$ & $620(270)$ & & $\mathrm{ns}$ & $103(1)$ & & $<0.0 .5$ \\
\hline Untreated $\mathrm{C}_{2}$ & - & $130(31)$ & & & $352(122)$ & & & $294(8(1)$ & & \\
\hline Untreated C3 & - & $142(20)$ & & & $680(150)$ & & & $307(51)$ & & \\
\hline Irradn GiHR & 7 & $3(2)$ & ns & $<0 \cdot 001$ & undetectable & $\mathrm{ns}$ & $<0 \cdot(x) 1$ & $16(10)$ & ns & $<() \cdot()(0) 1$ \\
\hline Irradn & 10 & $9(6)$ & & $<0 \cdot(0) 1$ & undetectable & & $<0 \cdot()(0) 1$ & $14(8)$ & & $<0 \cdot(0) 1$ \\
\hline Irradn GiHR & 10 & $3(1)$ & $\mathrm{ns}$ & $<0 \cdot(001$ & undetectable & ns & $<0 \cdot(0) 1$ & $38(24)$ & $\mathrm{ns}$ & $<0 \cdot()(0) 1$ \\
\hline Irradn & 14 & $4(5)$ & & $<0 \cdot 001$ & undetectable & & $<0 \cdot()(0) 1$ & $17(85)$ & & $<0 \cdot(x) 1$ \\
\hline Irradn GvHR & 14 & $1(1)$ & ms & $<0 \cdot 001$ & undetectable & $\mathrm{ns}$ & $<0 \cdot()(0) 1$ & $118(8.5)$ & $<0.05$ & $<() \cdot() 1$ \\
\hline
\end{tabular}

Irradn-irradiation; $\mathrm{p}^{*}$ - significance of diffeluce belwe sen irradiation and irradiation GvHR groups: CI: control to (ivHR without irradiation: $\mathrm{C} 2$ : control to rats with irradiation alons:; $($ i: control to rats with irradiation/GvHR. 
In the irradiated rats, damage to the mucosa was characterised by lengthening of the crypts and increase in CCPR, and counts of IEL were low on day 7. Irradiated rats with GvHR had significant enteropathy, with longer crypts and higher CCPR than in the matched irradiated animals. This crypt hyperplasia is a typical manifestation of moderately severe GvHR." Intraepithelial lymphocytes counts, however, reflected only the effects of irradiation.

Studies of jejunal MMC and serum RMCPII are summarised in Table 3. Irradiation caused the virtual disappearance of $\mathrm{MMC}$, there being only an occasional cell found in histological sections. This was confirmed by the absence of detectable RMCPII in jejunal homogenates, and serum concentrations of RMCPII were also very low. Similar changes in jejunal MMC were observed in the GvHR animals, although on day 14, serum RMCPII had risen significantly to $114 \mathrm{ng} / \mathrm{ml}$. At this time MMC were still absent from the jejunal mucosa used for the cell counts reported above, but examination of other fields in the sections showed that there was a patchy MMC infiltrate in the vicinity of Peyer's patches.

\section{Discussion}

These experiments have shown that there is a modest expansion in the number of jejunal MMC in unirradiated rats with semi-allogeneic GvHR, whereas irradiation, alone or associated with a GvHR, profoundly depletes MMC for at least two weeks. We can, therefore, confirm both, apparently contradictory previous reports of MMC changes in GvHR a rise in MMC count in unirradiated neonatal mice," and virtual disappearance of MMC in irradiated rats. ${ }^{3}$

Rat MMC can be distinguished from connective tissue mast cells (CTMC) morphologically, by fixation characteristics, pharmacological properties and by their granule mediators. ${ }^{+}$The granule protease RMCP I (rat mast cell protease 1) identifies CTMC and RMCPII (rat mast cell protease II) is associated with MMC. The systemic release of RMCPII from activated MMC enables their secretory activity to be monitored in vivo by assay of RMCPII in serum. ${ }^{56}$ With the sensitive ELISA used, nanogram quantities of the protease can be detected in the serum of normal rats. In the present series of experiments RMCPII content of jejunal homogenates closely paralleled MMC counts, and the concentrations of RMCPII in seralalso correlated directly with jejunal MMC count, there being no evidence of specific MMC activation or degranulation.

Irradiation and GvHR-associated effects on the jejunal mucosa were evaluated by measurements of tissue architecture and IEL counts. The results suggest that the jejunal mucosa of the rat and mouse differ in their susceptibility to the development of enteropathy in a GvHR. Despite significant splenomegaly and a rise in jejunal MMC count in unirradiated rats with GvHR, crypt length and CCPR were normal. In mice, a rise in IEL count is the earliest and most sensitive index of GvHR and other mucosal DTH reactions, ${ }^{1+10}$ but high IEL counts were not observed in any of the groups of rats with GvHR; indeed at seven days post-irradiation, rats with GvHR had lower IEL counts than unirradiated controls. On day 14 of the GvHR, however, there was striking and significant lengthening and hyperplasia of the crypts. These effects occurred despite the virtual absence of MMC, and indicate that MMC or their granule mediators are certainly not essential as mechanisms of GvHR enteropathy, and indeed might conceivably have a role in repair.

The mucosal specimens on which the above description is based had been taken from jejunum remote from Peyer's patches. In recent histological studies of Peyer's patches of irradiated animals we have observed early repopulation of MMC in the villi adjacent to Peyer's patches (Munro and Ferguson, unpublished). It seems likely that the rise to normal concentrations of the serum content of RMCPII in day $14 \mathrm{GvHR}$ rats is associated with the peripateh repopulation. Further investigations of this phenomenon are in progress.

There is now a substantial amount of evidence to support the theory that lymphokines, secreted by helper $\mathrm{T}$ cells in the lamina propria of the gut, can influence mitosis and differentiation of enterocytes, ${ }^{117}$ and that delayed type hypersensitivity reactions in the small bowel mucosa may produce an enteropathy with villus damage, crypt hyperplasia and disaccharidase deficiency. "11 is Cytotoxic lymphocytes, immune complexes and mast cell products must also be included as candidate effector mechanisms of tissue damage. ${ }^{519}$ For example, intestinal anaphylaxis has significant effects on electrolyte and water absorption. ${ }^{20}$ Mucosal mast cells may be involved in both immediate and delayed type hypersensitivity at mucosal surfaces, and abnormalities of mast cell counts in mucosal biopsies have led to the suggestions that MMC may be implicated in the mucosal damage of coeliac disease ${ }^{21}$ and inflammatory bowel disease." Relevant roles of MMC in these conditions, and the therapeutic potential of drugs which affect MMC function, remain to be explored. Nevertheless, the experiments described above indicate that the enteropathy of a DTH reaction can evolve in the virtual absence of MMC.

Perhaps the most interesting observation in this series of experiments is the recognition of extreme radiosensitivity of MMC. We are currently investi- 
gating the relevance of MMC degranulation to radiation-induced enteropathy and colitis.

We thank Anne MacKellar and George Newlands of the Moredun Research Institute, and June Swinton and the staff of the Animal Unit, Western General Hospital, for technical assistance. This work was supported by grants from the Wellcome Trust and Sandoz Pharmaceuticals. Dr A G Cummins was supported by a Fellowship from the Association of Commonwealth Universities, UK.

\section{References}

1 Ferguson A. Models of immunologically driven small intestinal damage. In: Marsh $\mathrm{MN}$, ed. Immunopathology of the small intestine. Chichester: John Wiley, 1987: 225-52.

2 Mowat AMcI. Ferguson A. Intraepithelial lymphocyte count and crypt hyperplasia measure the mucosal component of the graft-versus-host reaction in mouse small intestine. Gastroenterology 1982; 83: 417-23.

3 Levy DA. Wefald AF, Beschorner WE. Intestinal mast mucosal cell proliferation in graft-versus-host reaction in rats. Int Arch Allergy Appl Immunol 1985; 77: 186-8.

4 . Miller HRP. King SJ, Gibson S. Huntley JF. Newlands GFJ, Woodbury RG. Intestinal mucosal mast cells in normal and parasitized rats. In: Befus D, Densburg J, Bienenstock J, eds. Mast cell differentiation and heterogeneity New York: Raven Press, 1986: 239-48.

5 King SJ, Miller HRP. Anaphylactic release of mucosal mast cell protease and its relationship to gut permeability in Nippostrongylus-primed rats. Immunology 1984: 51: 653-60.

6 King SJ. Miller HRP, Woodbury RG, Newlands GFJ. Gut mucosal mast cells in Nippostrongylus-primed rats are the major source of secreted rat mast cell protease II following systemic anaphylaxis. Eur J Immunol 1986; 16: $151-5$

7 Simonson M. Graft-versus-host reactions. Their natural history and applicability as tools of research. Prog Allergy 1962: 6: 349-476.

8 Tannock IF. A comparison of the relative efficiencies of various metaphase arrest agents. Exp Cell Res 1967; 47: $345-56$.

9 Ferguson A. Murray D. Quantitation of intraepithelial lymphocytes in human jejunum. Gut 1971; 12: 988-94.
10 Strobel S, Miller HRP, Ferguson A. Human intestinal mucosal mast cells: Evaluation of fixation and staining techniques. J Clin Pathol 1981; 34: 851-8.

11 MacDonald TT, Ferguson A. Hypersensitivity reactions in the small intestine. 3. The effects of allograft rejection and of graft-versus-host disease on epithelial cell kinetics. Cell Tissue Kinet 1977; 10: 301-12.

12 Woodbury RG, Miller HRP. Quantitative analysis of mucosal mast cell protease in intestines of Nippostrongylus-infected rats. Immunology 1982; 46: 487-95.

13 Harper JF. Peritz' F test: Basic program of a robust multiple comparison test for statistical analysis of all differences among group means. Comput Biol Med 1984; 14: 437-45.

14 MacDonald TT, Ferguson A. Hypersensitivity reactions in the small intestine. 2. Effects of allograft rejection on mucosal architecture and lymphoid cell infiltrate. Gut 1976; 17: 81-91

15 Mowat AMcI, Ferguson A. Hypersensitivity reactions in the small intestinal mucosa of the mousec. 6. Pathogenesis of the graft-versus-host reaction in the small intestinal mucosa. Transplantation 1981; 32: 23843.

16 Strobel S, Ferguson A. Modulation of intestinal and systemic immune responses to a fed protein antigen, in mice. Gut 1986; 27: 829-37.

17 Elson CO, Reilly RW, Rosenberg IH. Small intestinal injury in the graft versus host reaction: an innocent bystander phenomenon. Gastroenterology 1977; 72: 886-9.

18 Lund EK, Bruce MG, Smith MW, Ferguson A. Selective effects of graft-versus-host reaction on disaccharidase expression by mouse jejunal enterocytes. Clin Sci 1986; 71: 189-98.

19 Ferguson A. Mowat AMcI. Immunological mechanisms in the small intestine. In: Wright $\mathrm{R}$, ed. Recent advances in gastro-intestinal pathology. Eastbourne: WB Saunders, 1980: 93-103.

20 Perdue MH, Chung M, Gall DG. Effect of intestinal anaphylaxis on gut function in the rat. Gastroenterology 1984; 86: 391-7.

21 Strobel S, Busuttil A, Ferguson A. Human intestinal mucosal mast cells: expanded population in untreated coeliac disease. Gut 1983; 24: 222-7.

22 Lloyd G, Green FHY, Fox H, Mani V, Turnberg LA. Mast cells and immunoglobulin $\mathrm{E}$ in inflammatory bowel disease. Gut 1975; 16: 861-6. 